\section{Solutions for surgeon-scientists}

\author{
John S. Ikonomidis, MD, PhD
}

The ongoing activity of physician-scientists is essential for the continued advancement of medicine. It is reasonable to assert that among the corpus of physicians and hospital/ institutional administrators, the foregoing statement is universally agreed upon. Unfortunately, although the notion that significant medical discoveries bring advancements in clinical care, prestige, and value to institutions is widely touted, when the so-called "rubber meets the road," meaningful support is sorely lacking; thus, the concept is undervalued and for all intents and purposes often ignored. Many barriers obstruct the success of physician-scientists, which in a very real way threaten the existence of these individuals. However, these barriers to success seem to be markedly magnified for surgeon-scientists, who face high demands for clinical productivity and revenue generation to maintain and protect the fiscal bottom line of their clinical divisions, departments and even whole hospitals irrespective of the onerous demands related to scientific investigation.

Factors contributing to the endangerment of academic clinicians and surgeons include (1) declining earning potential and decreased reimbursement for patient care in the face of increased costs of care and the ever-expanding use of novel expensive technologies and treatments; (2) the requirement for sufficient clinical volume and its related income to cover increasing hospital costs and surgeon salaries; (3) the increasing shift of many institutions to "funds-flow" financial models, which provide revenue for value based almost entirely on the clinical relative value unit, with no specific independent provision for value obtained from research productivity; (4) increasing competition and decreased federal budget allotment for National Institutes of Health (NIH) grant funding; and (5) the increasing effort and time away from clinical care (and personal life) necessary to perform meaningful research. ${ }^{1}$ Surgeons realize that compensation is much better and life is far easier working in clinical care compared with research.

\footnotetext{
From the Division of Cardiothoracic Surgery, University of North Carolina at Chapel Hill, Chapel Hill, NC.

Supported byNational Heart, Lung, and Blood Institute Grants 2R01 HL102121 and 1R21 HL148363.

Received for publication Sept 23, 2019; revisions received Oct 10, 2019; accepted for publication Oct 11, 2019; available ahead of print Dec 16, 2019.

Address for reprints: John S. Ikonomidis, MD, PhD, Division of Cardiothoracic Surgery, University of North Carolina at Chapel Hill, 3034 Burnett Womack Building, 160 Dental Circle, Chapel Hill, NC 27599-7065 (E-mail: john_ikonomidis@med. unc.edu).

J Thorac Cardiovasc Surg 2020;159:1917-20 0022-5223/\$36.00

Copyright (c) 2019 Published by Elsevier Inc. on behalf of The American Association for Thoracic Surgery

https://doi.org/10.1016/j.jtcvs.2019.10.179
}

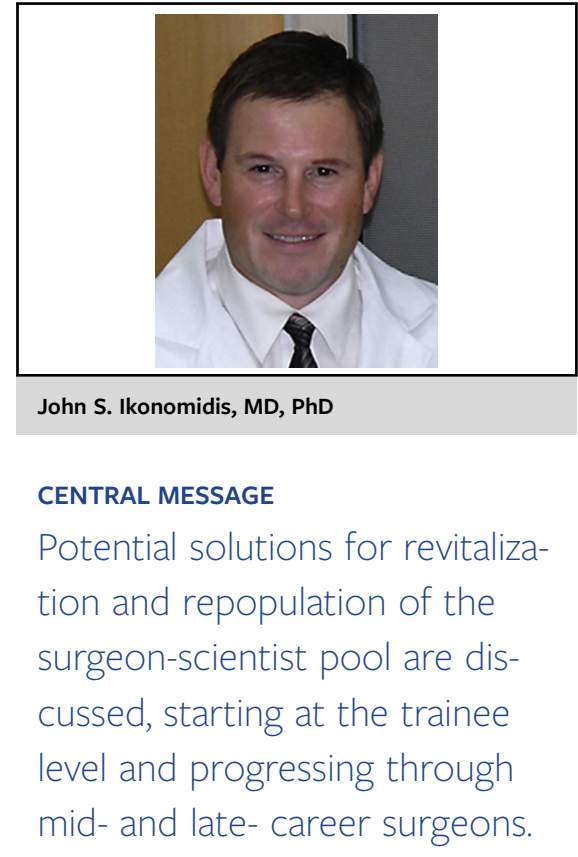

See Commentaries on pages 1921 and 1923.

Few surgeons are interested in receiving less compensation than their non-research-performing colleagues to perform research with no guarantee of ultimate funding. Related to this, leveling the playing field by using clinical revenues to support research can generate unhappiness with purely clinical partners who do not wish to support their less clinically active surgeon-scientist colleagues.

As the number of surgeon-scientists declines, the number of potential mentors for aspiring young surgeon-scientists also decreases. Many medical students and surgery residents begin their training interested in developing a research program, but on witnessing the daunting challenges that surgeon-scientists face, decide to pursue non-researchenhanced clinical careers. In addition, when most surgical trainees finally graduate to independent practice, they are hoping to attain a reasonable lifestyle outside of the hospital that does not involve the commitment of evenings and weekends to research and writing.

The foregoing topics and more were discussed in a recent article in the Journal, ${ }^{1}$ and numerous other publications on the looming shortage of physician-scientists have been published in such journals as the Annals of Surgery, ${ }^{2,3}$ New England Journal of Medicine, ${ }^{4}$ and Journal of the 
American Medical Association Surgery. ${ }^{5,6}$ One example is an $\mathrm{NIH}$ funding data review coupled with a survey that was distributed to 2504 members of the Association for Academic Surgery and Society of University Surgeons to determine factors impacting success in research. The NIH data revealed a $27 \%$ decline in the proportion of NIH funding to surgical departments relative to total NIH funding from 2007 to 2014. Sixty-eight percent of the 1033 surgeons responding to the survey did not believe that surgeons can be successful basic scientists in today's environment. ${ }^{2}$ As concerning as the current situation is, the prospect of change to promote, enhance, and reinvigorate the surgeon-scientist pool is at least equally daunting.

Potential solutions for repopulation and revitalization of the surgeon-scientist sector should start at the trainee level. As suggested by Jain and colleagues, ${ }^{4}$ medical school curricula can be reorganized to include expanded basic science foundational coursework. Medical students should be made aware of and encouraged to apply to extrainstitutional research opportunities, such as the Sarnoff Fellowship, National Institutes of Health Medical Research Scholars program, and Stanford's "Discovery Curriculum" and Berg Scholars program. During residency and fellowship, consideration should be given to the addition of a formal research curriculum, which could include dedicated didactic research rotations with sessions in study design, statistical analysis, and research regulations, as well as identification of mentors to assist in developing longitudinal research projects. ${ }^{7}$ Research opportunities for trainees should receive appropriate funding with experienced mentors, guaranteed protected time (ie, not rotating research residents into the clinical call schedule), and even debt relief as appropriate. The NIH T32 training paradigm has proven to be highly successful and to have a lasting impact. A study by Narahari and associates ${ }^{8}$ showed that trainees who were supported by a CT T32 grant were more likely to pursue cardiothoracic surgery after residency, to publish manuscripts during residency years, to obtain subsequent NIH funding, and to pursue advanced fellowships. During these critical formative years, appropriately supported trainees aspiring to a research career will consider their clinical milieu and the available literature and formulate important questions that they will then study as part of development of their dual-career path. The valuable time spent away from clinical activity developing a research interest should not be demeaned by other residents and faculty. Consideration should be given to rebranding these so-called "lab years" as an important aspect of professional development. ${ }^{6}$

Making the proper transition from trainee to junior faculty clinician-investigator is very challenging and often unsuccessful. Early trainees must balance their expanding responsibilities of paying off student debt, satisfying the early clinical needs to which they are assigned and raising a family against formulating relevant and testable research questions and executing these studies correctly in supervised environments with adequate resources. Finding the appropriate mentor is critical to the success of a young faculty member at this stage. ${ }^{3}$ Some important qualities of good mentors include willingness to commit the time and effort to being a mentor, flexibility and understanding of the demands of the mentee; a personality matching that of the mentee; familiarization with the area of study; demonstration of a positive attitude and actions as a positive role model; willingness to share skills, knowledge, and expertise; and a track record of success in research. Many surgery departments have a mentorship program in which young surgeon-investigators are matched with senior investigators from day 1 . During frequent meetings between the mentors and their mentees, research interests are defined, study outlines are crafted, the need for additional collaboration is identified, and funding strategies are discussed and implemented. Mentors must be willing to read and critique manuscripts and grant proposals and to take a strong interest in the success of their mentee.

At the divisional or departmental level, robust and sustained support must be provided for junior faculty embarking on a surgeon-investigator career. The pressures associated with obtaining funding can be enormous coupled with the many new and important responsibilities thrust on these individuals. As such, as unpressured, understanding, and supportive an environment as possible should be created to provide young faculty members the security and enthusiasm to conduct research and to be persistent in the face of triaged grant proposals and manuscript rejections. They must be meaningfully mentored through the many reworkings of the abstracts, manuscripts, and funding proposals they will write. They should have protected time for research without being made to feel guilty or to believe that they are a burden to the rest of their group. Partners should be understanding and supportive.

Many young faculty members are expected to make the transition from an initial work contract predicated on a fixed salary structure to a "practice plan," the reimbursement for which is based on clinical output. Some, but not all, such plans may also include a bonus structure that rewards academics, but the potential bonus associated with academic productivity is usually relatively small compared with the rewards associated with clinical activity. The funds to support this type of bonus are typically extracted from clinical revenues, with the unfortunate irony of this being that the amount of money available for distribution for academic productivity depends on the magnitude of clinical productivity. 
There are many potential pitfalls to a purely clinically based reimbursement structure, ${ }^{9}$ and such a structure can result in a fundamental change in priorities for young faculty members with the realization that every hour spent in the lab could have been spent in the operating room generating clinical productivity and income for themselves. Thus, it can be argued that this type of salary structure, which provides rewards based either directly or indirectly on clinical productivity, creates an environment that discourages research productivity. It has been suggested that ideally, dedicated young faculty should be subjected not to this type of salary structure, but rather to one not critically dependent on clinical productivity. The finances associated with such a shift would likely pose problems for division heads and department chairs trying to keep their assigned budgets balanced. This is where their respective College of Medicine or hospital administration would be expected to commit funds to support these important individuals. Although these committed funds would not be reimbursed through work relative value units (RVUs) or diagnosisrelated groups (DRGs), institutions can recover money from supporting research through royalties from drug and device patents, and also from holding courses and meetings to teach and showcase advancements by their research faculty. Philanthropic contributions can be redistributed to support research rather than purely clinical programs. The ultimate goal is to create a secure, encouraging, desirable environment in which young surgeon-investigators can thrive.

As surgeon-investigators advance their careers, they must manage their continued performance of research while responding to increasing clinical demands, service to societies, and increasing leadership or administrative roles in their respective institutions. The ultimate transition to division head or department chair marks a milestone often accompanied by the cessation of research activity, owing to the attendant significant increase in administrative responsibility. ${ }^{10}$ This occurrence is quite unfortunate, because these individuals would now have the opportunity to "lead by example" and help oversee the identification of and support for young faculty surgeon-scientists. Numerous avenues to sustaining the careers of mid-career surgeon-scientists include establishing specific guidelines for salary and an optimal balance of clinical and research efforts, ${ }^{4}$ simplification of the process required for Institutional Review Board (IRB) and Institutional Animal Care and Use Committee (IACUC) approval for new and ongoing studies, simplified grant submission processes, and relaxed criteria for providing ongoing funding for established and productive investigators. The development of a consortium of physician-scientist leaders who are willing to find ways to stimulate research by physicians to address intractable medical problems can change the trajectory of and improve health care. ${ }^{4}$ Simplification of maintenance of certification and hospital credentialing have also been suggested as ways to liberate time. ${ }^{4}$

The steady decline of surgeons performing translational research is an issue that must be confronted and reversed. Many important questions remain to be answered in major investigative areas, such as oncology, congenital disease, vascular biology, regenerative medicine, and transplantation. Surgeon-scientists bring a heightened rigor to their everyday clinical work, which improves the teaching of students and residents and also promotes an enhanced quality of the work done by peers.

Many institutions have transitioned to a productivitybased reimbursement model, which shifts control of clinical revenues generated from division chiefs and department chairs to either hospital administration, the College of Medicine, or both. One result of this transition is elimination or a substantial decrease in discretionary reserves that these surgical leaders can use to support research. Thus, the charge for prioritization of research and enhanced support of surgeon-scientists must necessarily translate to the larger administrative forces outside of surgery. Research should be considered a program very much like clinical programs, with allocation of resources and dollars each year for robust support. Only with these expanded resources and development of an institution-wide culture that craves, supports, and rewards research will the surgeon-scientist pool be restored and further expanded.

\section{Conflict of Interest Statement}

Author has nothing to disclose with regard to commercial support.

\section{References}

1. Ikonomidis JS, Menasché P, Kreisel D, Sellke FW, Woo YJ, Colson YL. Attrition of the cardiothoracic surgeon-scientist: definition of the problem and remedial strategies. J Thorac Cardiovasc Surg. 2019;158:504-8.

2. Keswani SG, Moles CM, Morowitz M, Zeh H, Kuo JS, Levine MH, et al. The future of basic science in academic surgery: identifying barriers to success for surgeon-scientists. Ann Surg. 2017;265:1053-9.

3. Goldstein AM, Blair AB, Keswani SG, Gosain A, Morowitz M, Kuo JS, et al. A roadmap for aspiring surgeon-scientists in today's healthcare environment. Ann Surg. 2019;269:66-72.

4. Jain MK, Cheung VG, Utz PJ, Kobilka BK, Yamada T, Lefkowitz R. Saving the endangered physician-scientist - a plan for accelerating medical breakthroughs. N Engl J Med. 2019;381:399-402.

5. Kibbe MR, Velazquez OC. The extinction of the surgeon scientist. Ann Surg. 2017;265:1060-1.

6. Mansukhani NA, Patti MG, Kibbe MR. Rebranding "the lab years" as "profes sional development" in order to redefine the modern surgeon scientist. Ann Surg. 2017;266:937-8.

7. Marbach JA, Almufleh A, Froeschl M, Hibbert B. The next generation of physician-scientists: adapting to academic cardiology in the 21st century. Can J Cardiol. 2018;34:1225-8

8. Narahari AK, Charles EJ, Mehaffey JH, Hawkins RB, Schubert SA, Tribble CG, et al. Cardiothoracic surgery training grants provide protected research time vital to the development of academic surgeons. J Thorac Cardiovasc Surg. 2018;155 2050-6. 
9. Gunderman RB. The perils of paying academic physicians according to the clinical revenue they generate. Med Sci Monit. 2004;10: RA15-20.
10. Hebert RS, Elasy TA, Canter JA. The Oslerian triple-threat: an endangered species? A survey of department of medicine chairs. Am J Med. 2000;109:346-9. 